\title{
Introduction: the decentralization formula
}

It's nothing new. The relationship between law and technology has already existed for several millennia. Human behaviors in society have been defined by written rules since antiquity; while technology - a means to fulfill a purpose - is even older. And both the law and technology are dynamic because they are designed by humankind, for humankind. Describing their relationship as ancestral and evolutionary is an understatement. In fact, technology has been regulated since the very existence of the Rule of Law. For example, the Code of Hammurabi (1754 BC) regulated the negligent opening of a canal for irrigation by a man. It imposed compensation for the misuse of this technology. ${ }^{1}$

What is new is the importance of law and technology interaction, especially for digital technologies. The prevalence of computer code in organizing society is growing every day. Whether we educate or entertain ourselves, shop, communicate with friends, arrange trips or look for specific information, digital technologies are increasingly shaping the realm of possibilities. They are the bedrock upon which our modern societies are built.

Moreover, many digital technologies (are developed to) escape the rule of law; or at least, (to) prevent its full application. ${ }^{2}$ Every day, these technologies - such as blockchain - advance a little bit faster, become autonomous from humans and increasingly determine the organization of our societies. Although the law remains (one of) the primary constraint(s) on human behavior, it can no longer prevail unconditionally on digital architectures. West Coast code (computer programming) is acquiring the means to oppose East Coast code (legislation and regulations). For these reasons, a confrontational approach to law and technology no longer maximizes the common good, as it has in centuries past.

Whatever one thinks about the new importance of code in society, it justifies a novel approach to "law and technology." This book is an argument about the need for cooperation between the two. To paraphrase Sun Tzu, ${ }^{3}$ faced with the

Code of Hammurabi, Article 55 (1754 BC).

Thibault Schrepel, "Anarchy, State, and Blockchain Utopia: Rule of Law versus Lex Cryptographia," in General Principles and Digitalisation (Hart Publishing, 2020).

3 Sun Tzu, L'art de la Guerre, trans. Francis Wang (Flammarion, 1972). 
danger of a destructive confrontation, only collaboration "like the right hand with the left hand" will maximize the common good. ${ }^{4}$

That cooperation can take different forms, depending on the nature of the relationship between laws and technologies. I distinguish three situations: two at each end of the spectrum depicted in Figure 0.1, and one in the middle.

\section{Tension $\longleftrightarrow$ Harmony}

(between law and technology)

(between law and technology)

Figure $0.1 \quad$ A scale of the relationship between law and technology

First, there are situations in which technology systematically opposes the law. The left side of the spectrum represents these. Here, one must first analyze whether the aim pursued by the technology benefits the common good and under what circumstances. If that is the case, one must change the law to enable the technology. If not, collaboration between law and technology should lead to the domination of the rule of law. Two outcomes are possible: either redirecting the technology or outlawing it altogether. All discussions regarding blockchain applications designed to evade the rule of law are located on this spectrum's left side.

Second, law and technology may have an ambiguous relationship, where they oppose and complement each other in different aspects. In that case, collaboration seeks to enable the - necessarily partial - achievement of two different objectives without putting either at risk. The example of blockchain and privacy protection is telling in this respect. While blockchain's immutable nature is difficult to reconcile with the right to rectification or erasure, blockchain's encryption makes it possible to protect transactions' identity (as I will explain).

Finally, there are situations in which law and technology pursue the same aim.

4 In this book, common good maximization will be analyzed from the angle of competitiveness. It should also be addressed from a more human rights perspective. The idea that technology can also liberate citizens from oppressive states is a significant point that George Orwell dodged in his famous 1984, yet an important one embodied by blockchain. 
The right side of the spectrum represents these. Here, one must ensure that each can rely on the other. This is notably the case for blockchain and antitrust law. While from time to time they will be antagonistic, they will mostly benefit from cooperation. One must identify which confrontations may endanger blockchain or antitrust law, and determine how they can be eliminated while maintaining their complementary aspects.

This paradigm is new for antitrust law. Private companies have long been (and still are) pursuing a different goal than antitrust agencies. That explains why tech giants are at the heart of many recent cases. Regardless of the merits of these decisions, and although one may regret the confrontational approach taken by the legal and tech communities, there is a logical explanation.

While the vast majority of these companies' activities benefit consumers, some end up reducing consumer welfare because tech giants are not pursuing that objective. Like all other companies, they are guided by profit maximization; whereas antitrust law aims to protect consumers by ensuring the proper functioning of markets. These two agendas are generally aligned, but are sometimes at odds with each other. As we shall see together, the creation of the Sherman Act resulted from the desire to respond to the practices of large companies (e.g., Standard Oil). At the heart of their relationship is a fundamental mistrust, resulting in the spending of immense financial and human resources.

Things are different for antitrust law and blockchain. They are complementary. On the one hand, antitrust law protects the competitive process by eliminating forms of coercive control. On the other hand, blockchain seeks to eliminate centralized and vertical forms of control (and disrupt such existing structures). In a sense, antitrust law aims to constrain the exercise of power through the rule of law; while blockchain seeks to do so through technical means. And while some entities running on blockchain ecosystems are profit driven, the technology architecture (tends to) align their goals with antitrust law. Both end up taking part in the decentralization of transactional power. They do not speak the same language, but they share the same ambition.

It goes even further than this. Besides seeking the same aim, the combination of antitrust law and blockchain can maximize their common goal to a degree that would be unthinkable if they were acting on their own. The same is true for all interactions in the first quadrant (top-right corner) of Figure 0.2 - that is, where a body of laws and technology naturally pursue the same $a^{5}{ }^{5}$ and seek cooperation.

5 That statement is deterministic, see Thibault Schrepel, "Law and Technology Realism," MIT Computational Law Report, August 14, 2020, https://perma.cc/C5VU -DKD4. 


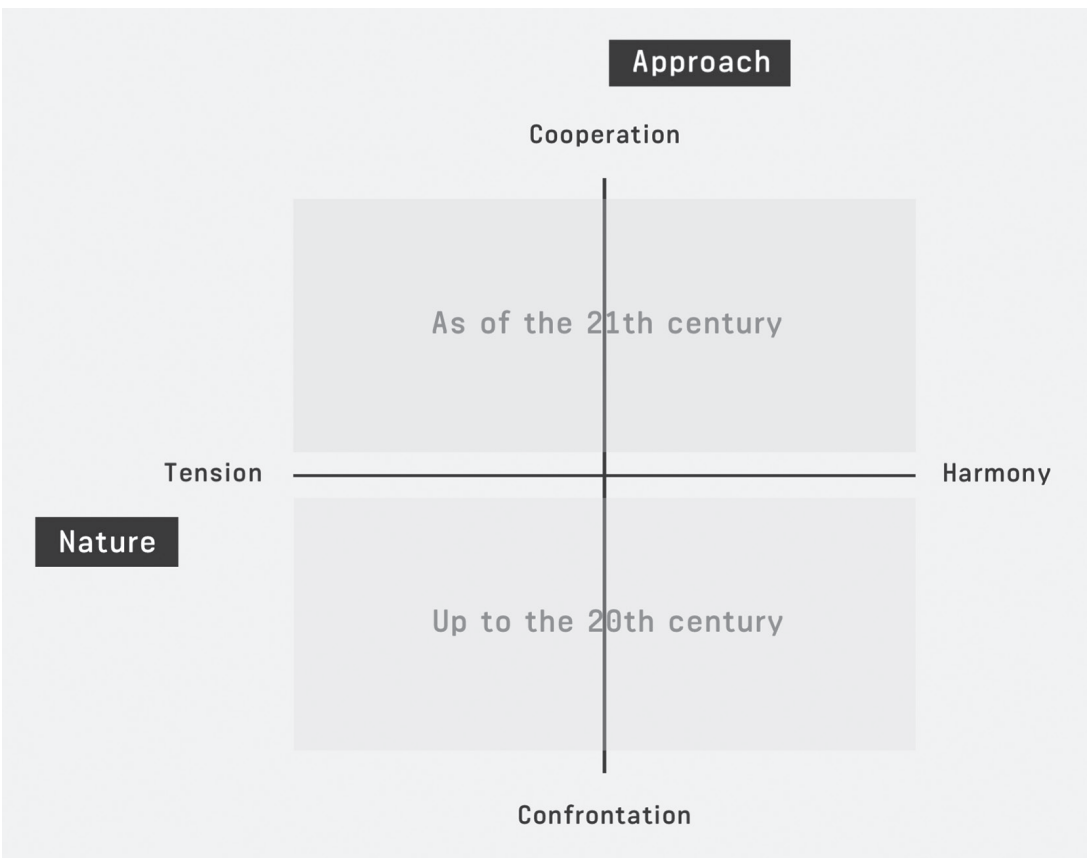

Figure 0.2 Law and technology interactions through the years

This book addresses that first quadrant. Collaboration between law and technology is instinctively appealing; after all, who would not want them to benefit from each other? But I fear that dissenting voices will become more pressing when talking about the terms of this collaboration. The return to reality will be difficult; as in any marriage, the alliance of antitrust law and blockchain will require mutual concessions.

My goal is thus to convince readers that efficiencies arise from collaboration between antitrust law and blockchain (the big picture); and that this should guide the treatment of all interactions (the small picture), including negative ones. The book's title reflects that intention. Whereas the classical conception of the rule of law tends towards a "Blockchain vs. Antitrust" approach, I want to set the terms for a "Blockchain + Antitrust" approach, where technology is aligned with regulators' intentions.

The task before me is not an easy one; I approach it with the utmost humility. First, it is necessary to change the mentalities of both legal scholars and technologists. This can be done by highlighting the mutual benefits that stem from cooperation between each of the two communities. A single book won't be 
enough to achieve that goal; the process will take many years. In the meantime, the use of blockchains to violate antitrust law will create numerous tensions. The same will go for the other antitrust infringements committed within blockchain ecosystems.

The confrontational approach must nonetheless be resisted, mainly because a non-cooperative application of antitrust law would have the effect of reducing blockchain's usefulness. Thus, it would give the impression that blockchain is not a valuable ally in achieving the common aim. Policymakers should not fall into this negative spiral.

With that in mind, and since the best defense is to attack, this book discusses the frictions between blockchain and antitrust law. It explains how blockchains can (be used to) infringe antitrust law. In other words, while blockchain technology has many benefits, it also has flaws and limitations. This book lays bare all of these features and interactions. It examines what I refer to as "blockchain antitrust" - that is, potential antitrust infringements by and within blockchains. ${ }^{6}$ It also discusses how cooperation between these two spheres could take place in that context.

Here is our roadmap. The first part shows that blockchain and antitrust law share a common aim: decentralization. The second part shows that blockchain could still (be used to) infringe antitrust law and create artificial forms of centralization. In the third part of the book, I analyze how to tackle these infringements while making sure not to diminish blockchain's role as an ally.

6 Thibault Schrepel, "Is Blockchain the Death of Antitrust Law? The Blockchain Antitrust Paradox," Georgetown Law Technology Review 3, no. 2 (2019): 281, 292. 